\title{
Role of Estimation of Serum Ferritin, Vitamin B12 and Folic Acid in Management of Beta Thalassemic Children
}

\author{
Singla $\mathbf{H}^{1}$, Goyal $\mathbf{G}^{2}$ \\ ${ }^{1}$ Dr. Heena Singla, Assistant Professor, Biochemistry, ${ }^{2}$ Dr Gitanjali Goyal, Professor, Biochemistry, Both authors are \\ affiliated with Department of Biochemistry, Baba Farid University of Health Sciences, Faridkot, Punjab, India.
}

Address for Correspondence: Dr. Heena Singla, E-mail id: drheenasingla@gmail.com

\begin{abstract}
Objective: To estimate the levels of serum Ferritin, Vitamin $\mathrm{B}_{12}$ and Folic acid in beta thalassemic children. Introduction: Beta thalassemia is the most common genetically transmitted haematological disorder in Indian children. In thalassemia, there is ineffective erythropoiesis which can be either due to excess iron accumulation, or low vitamin $\mathrm{B}_{12}$ and folate status. Study Design: The case-control study was carried out at G.G.S. Medical College and Hospital, Faridkot in department of Biochemistry in collaboration with department of Paediatrics. Materials and methods: In this case-control study, 50 children with with beta thalassemia major in the age group of 4 to 8 years were studied for estimation of serum ferritin, vitamin $\mathrm{B}_{12}$ and folic acid. The control group consisted of 50 age and sex matched healthy children. Results: The study group had much higher serum ferritin levels as compared to healthy controls $(\mathrm{p}<0.001)$. On other hand, the thalassemic children had much lower vitamin $\mathrm{B}_{12}$ level in comparison with healthy controls $(\mathrm{p}<0.001)$. The folic acid levels were also much lower in thalassemic children as compared to healthy controls $(p<0.001)$. Conclusion: Biochemical screening for levels of serum ferritin, vitamin $\mathrm{B}_{12}$ and folic acid is of paramount importance in management of thalassemic children. Supplementation of vitamin $B_{12}$ and folic acid could be helpful to improve erythropoiesis in thalassemic children who have proven deficiency of these vitamins, though further studies are needed to establish this hypothesis.
\end{abstract}

Key words: Beta thalassemia, Erythropoiesis, Ferritin, Folic acid, Vitamin $\mathrm{B}_{12}$

\section{Introduction}

Beta thalassemia is an autosomal recessive genetic disease. The cause is partial or complete lack of ability to synthesise beta chains of the haemoglobin [1]. This process of beta globin chain synthesis is controlled by a gene located on chromosome 11. There can be more than 200 mutations of this gene, leading to varying degrees of inability to synthesise beta chains of haemoglobin. In thalassemia major, there is complete lack of ability to synthesise beta chains of haemoglobin.

This leads to chronic haemolysis and severe anaemia [2]. Patients present with varying degrees of anaemia from early childhood and are transfusion dependent. According to an epidemiological study, beta thalassemia is the most common genetically transmitted haematological disorder in Indian children [3].

Manuscript received $10^{\text {th }}$ July 2016

Reviewed: $25^{\text {th }}$ July 2016

Author Corrected: $5^{\text {th }}$ August 2016

Accepted for Publication $17^{\text {th }}$ August 2016
Iron metabolism in thalassemia- Normally, the amount of iron (20-30 mg/day) needed for daily production of 300 million new RBCs is provided mostly by the iron which is recycled by macrophages [4]. The iron stored in macrophages is safe, and it does not lead to oxidative stress [5]. Duodenal absorption in normal persons is approximately $1-2 \mathrm{mg} / \mathrm{day}$, which is balanced with iron excretion of 1-2 $\mathrm{mg} /$ day. In thalassemic patients, there is increased iron absorption (3-9 mg/day) [6]. This causes increase in body's iron burden. Additionally in thalassemia major patients, regular blood transfusions lead to double iron accumulation (420 $\mathrm{ml}$ of transfused blood is equivalent to $200 \mathrm{mg}$ of iron).

In these patients, the excess iron saturates the plasma transferrin, which then transfers the iron to a storage protein called apoferritin. Thus the storage protein ferritin is formed. Ferritin is a $450 \mathrm{kDa}$ protein 
consisting of 24 subunits which is present in every cell type [7]. The ferritin levels measured have a direct correlation with the total amount of iron stored in the body. This fact applies in all types of anaemia of chronic disease due to any cause [8]. In iron overload disorders such as haemochromatosis, serum ferritin levels have been found to be abnormally increased [9].

Role of vitamin B12 and Folic acid- Vitamin $B_{12}$ and folic acid are essential nutrients for erythropoiesis. Deficiency of either of these vitamins leads to megaloblastic anaemia [10]. Vitamin $\mathrm{B}_{12}$ defficiency may also cause severe neurological deficit. Low serum folate has well been described in homozygous beta thalassemia [11]. Reports on vitamin $B_{12}$ status in thalassemic patients are at variance.[12] In homozygous beta thalassemia, erythropoiesis is depressed. The cause can be iron overload [13] or deficiency of these vitamins.

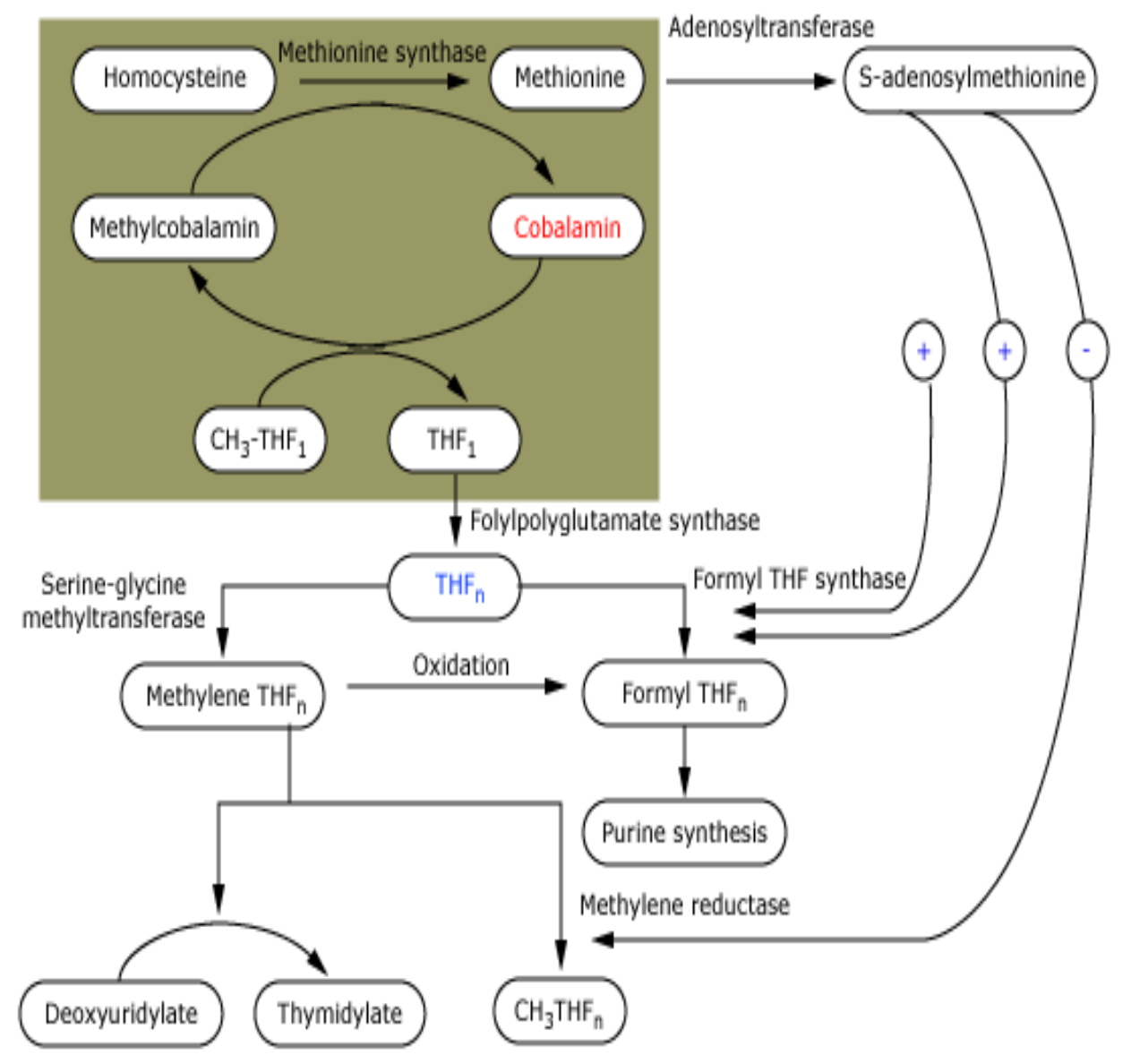

Role of Interdependent cofactor activity of vitamin B12 and folate in intracellular DNA synthesis in RBCs.

The + signs indicate enhancement, and the - signs indicate inhibition. Demethylation of methyl-tetrahydrofolate (CH3THF) to THF is a critical step in DNA synthesis because THF is the substrate for the enzyme that converts (THF)-1 to the polyglutamated form $(\mathrm{THF})_{\mathrm{n}}$. Only polyglutamated $(\mathrm{THF})_{\mathrm{n}}$ participates in purine synthesis.

\section{Materials and Methods}

Study Design- The study was carried out at G.G.S. Medical College and Hospital, Faridkot in department of Biochemistry in collaboration with department of Paediatrics. The study was approved by institutional ethical committee of G.G.S. Medical College and Hospital, Faridkot. It was a case-control study. 50 children with with beta thalassemia major in the age group of 4 to 8 years were studied for estimation of serum ferritin, vitamin $B_{12}$ and folic acid. The control group consisted of 50 age and sex matched healthy children. Detailed history and complete physical examination was recorded. Informed written consent was taken from all the study subjects. 


\section{Exclusion criteria}

1. Those on iron or vitamin B-complex supplements.

2. Chronic liver failure as these patients has low vitamin $B_{12}$ levels.

3. Patients on anti-convulsants and anti-cancer drugs as these patients have low folate levels.

4. Patients with acute infections and acute inflammatory diseases, as these patients show false high ferritin levels. This is because ferritin is an acute phase reactant.

5. Chronic renal failure.

Blood sample collection: About $10 \mathrm{ml}$ of peripheral venous blood was collected from all the study subjects.

\section{Investigations}

Routine investigations: These included:

1. Haemoglobin levels and complete blood count. These were done on Beckman Coulter cell counter. Peripheral blood smear was studied for red blood cell morphology.

2. Biochemical investigations included fasting blood glucose, serum electrolytes, liver function tests (SGOT, SGPT, ALP, serum bilirubin) and renal function tests(Blood urea and serum creatinine). The tests were done on Beckman coulter AU-480 fully automated analyser. These tests were done to rule out patients of chronic liver failure and chronic renal failure.

Special investigations: These included :

1. Serum ferritin which was measured on Immulite 1000 chemiluminescence. It is based on the principle of solid phase, two site immunometric, chemiluminescence assay. [14] Its normal value in males is $28-365 \mathrm{ng} / \mathrm{ml}$, and its normal value in females is $5-148 \mathrm{ng} / \mathrm{ml} .[15]$

2. Serum vitamin $\mathbf{B}_{12}$ and folic acid. These parameters were measured on Access-2 chemiluminescence machine. Measurement of vitamin $B_{12}$ and folic acid is based on the principle of competitive binding immunoenzymatic assay. [16] Vitamin $B_{12}$ or folic acid in the sample binds to the conjugate, preventing the conjugate from binding to the solid phase antibody. After incubation in a reaction vessel, the material bound to the solid phase is held in a magnetic field while the unbound material is washed off. Then the chemiluminescent substrate Lumi-Phos 530 is added to the vessel and light generated by the reaction is measured with a luminometer. The photon (light) production is inversely proportional to the concentration of vitamin $B_{12}$ or folic acid in the sample. Normal value of vitamin $B_{12}$ is 180-971 pg/ml. [17] And normal value of folic acid is more than $6 \mathrm{ng} / \mathrm{ml} .[18]$

Statistical analysis: Statistical analysis of results was done using SPSS 16 version software. Baseline characteristics of the study subjects were presented as mean + standard deviation. ANOVA (Analysis of Variance) was used for multiple comparisons of parameters between the two groups. $p$ value was calculated to know the significance of difference in the individual variables among the two groups. $\mathrm{p}$ value $<0.05$ was considered to be statistically significant, while $\mathrm{p}$ value < 0.001 was considered to be highly significant. Pearson's correlation coefficient ( $\mathrm{r}$ value) was calculated between the values of serum ferritin and serum vitamin $B_{12}$, and also $r$ value was calculated between the values of serum ferritin and folic acid.

\section{Results}

For the present case-control study, subjects were taken after age and sex matching. We compared all the important biochemical parameters between the two groups which included serum ferritin, vitamin B12 and folic acid.

As shown in Table 1, beta thalassemic children had ferritin levels in the range of $2637.4-4855.8 \mathrm{ng} / \mathrm{ml}$, while in healthy controls, ferritin levels were in the range of $152.8-201.2 \mathrm{ng} / \mathrm{ml}$. (Normal value of ferritin is $28-365 \mathrm{ng} / \mathrm{ml}$ in males, and $5-148 \mathrm{ng} / \mathrm{ml}$ in females). So ferritin levels were much higher in the beta thalassemic children(Group A) in comparison with the healthy controls(Group B) $(\mathrm{p}<0.001)$. 
Table-1: Comparison of serum ferritin, vitamin $B_{12}$ and folic acid levels in $\beta$-thalassemia patients and healthy controls*

\begin{tabular}{|c|c|c|c|}
\hline $\begin{array}{c}\text { Biochemical } \\
\text { Parameters }\end{array}$ & $\begin{array}{c}\text { Group A } \\
(\boldsymbol{\beta} \text {-thalassemia patients) } \\
\mathbf{n = 5 0}\end{array}$ & $\begin{array}{c}\text { Group B } \\
\text { (Healthy controls) } \\
\mathbf{n = 5 0}\end{array}$ & \begin{tabular}{c} 
p value $\dagger$ \\
\hline Ferritin \\
$(\mathrm{ng} / \mathrm{mL})$
\end{tabular} \\
\hline $\begin{array}{c}\text { VitaminB } 12 \\
(\mathrm{pg} / \mathrm{mL})\end{array}$ & $245+57.7$ & $509+112.2$ & 0.0001 \\
\hline Folic acid \\
$(\mathrm{ng} / \mathrm{mL})$
\end{tabular}

*The values are expressed in mean + S.D

$\dagger \mathrm{p}$ value $<0.001$ means highly significant.

Table-2: Coefficient of correlation between serum ferritin and folic acid, and between serum ferritin and vitamin $B_{12}$ in $\beta$-thalassemia patients (Group $\left.A\right)$.

\begin{tabular}{|c|c|c|}
\hline $\begin{array}{c}\text { Biochemical parameters } \\
(\mathrm{n}=50)\end{array}$ & $\mathrm{r}^{*}$ & $\mathrm{p}^{\dagger}$ \\
\hline Ferritin and Folic acid & -0.483 & $<0.001$ \\
\hline Ferritin and Vitamin B12 & -0.724 & $<0.001$ \\
\hline
\end{tabular}

r value: Pearson's coefficient of correlation

* Negative $r$ value means negative correlation between the concerned parameters.

$\dagger \mathrm{p}$ value $<0.001$ means highly significant.

Group A (Beta thalassemic children) had vitamin $\mathrm{B}_{12}$ levels in the range of 187.3 - $302.7 \mathrm{pg} / \mathrm{ml}$. In comparison, Group B ( healthy controls) had serum vitamin $\mathrm{B}_{12}$ in the range of $396.8-621.2 \mathrm{pg} / \mathrm{ml}$. (Normal value of vitamin $\mathrm{B}_{12}$ is $180-971$ $\mathrm{pg} / \mathrm{ml}$ ). Hence serum vitamin $\mathrm{B}_{12}$ levels were significantly lower in beta thalassemic children as compared to healthy controls $(\mathrm{p}<0.001)$.

The levels of serum folic acid in beta thalassemic children (Group A) was in the range of $3.49-6.55 \mathrm{ng} / \mathrm{ml}$, while in healthy controls (Group B), seum folic acid levels were in the range of $10.1-14.3 \mathrm{ng} / \mathrm{ml}$. (Normal value of serum folic acid is $>6 \mathrm{ng} / \mathrm{ml}$ ). Hence the levels of serum folic acid were significantly lower in beta thalassemic children as compared to healthy controls $(\mathrm{p}<0.001)$. The $\mathrm{p}$ value $<0.001$ established significant difference in the levels of all these three parameters between the two groups.

Pearson's correlation coefficient was calculated between the concerned parameters. In thalassemic patients (Group A), a strong negative correlation was observed between serum ferritin and folic acid $(r=-0.483, p<0.001)$, indicating high level of significance.

Also, there was strong negative correlation between serum ferritin and vitamin $\mathrm{B}_{12}$ levels in these study subjects $(r=-0.724, p<0.001)$. Hence with increasing levels of serum ferritin, there was corresponding decrease in the levels of serum vitamin $\mathrm{B}_{12}$ and folic acid.

Scatter plots representing correlation between serum ferritin and vitamin $\mathrm{B}_{12}$, and between serum ferritin and folic acid in $\beta$-thalassemia patients have been shown in Figure 1 and 2 respectively. 


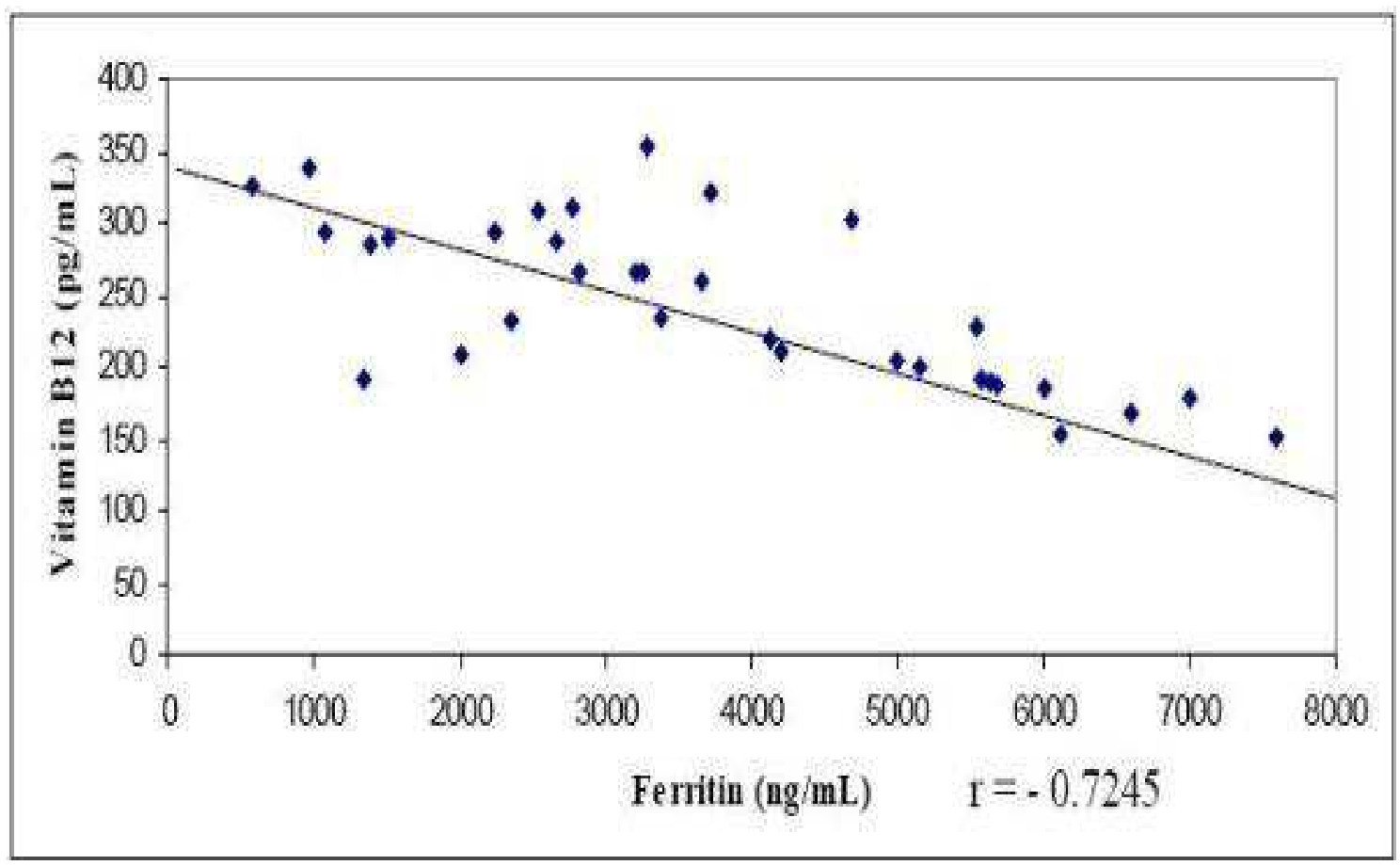

Figure-1: Scatter plot showing correlation between serum ferritin and vitamin B12 levels

As can seen from above figure, with increase in serum ferritin levels, there was corresponding decrease in the levels of serum vitamin $B_{12}$ in beta thalassemic children. Pearson's correlation coefficient ( $r$ value of -0.7245) indicates strong negative correlation between serum ferritin and serum vitamin $B_{12}$ levels.

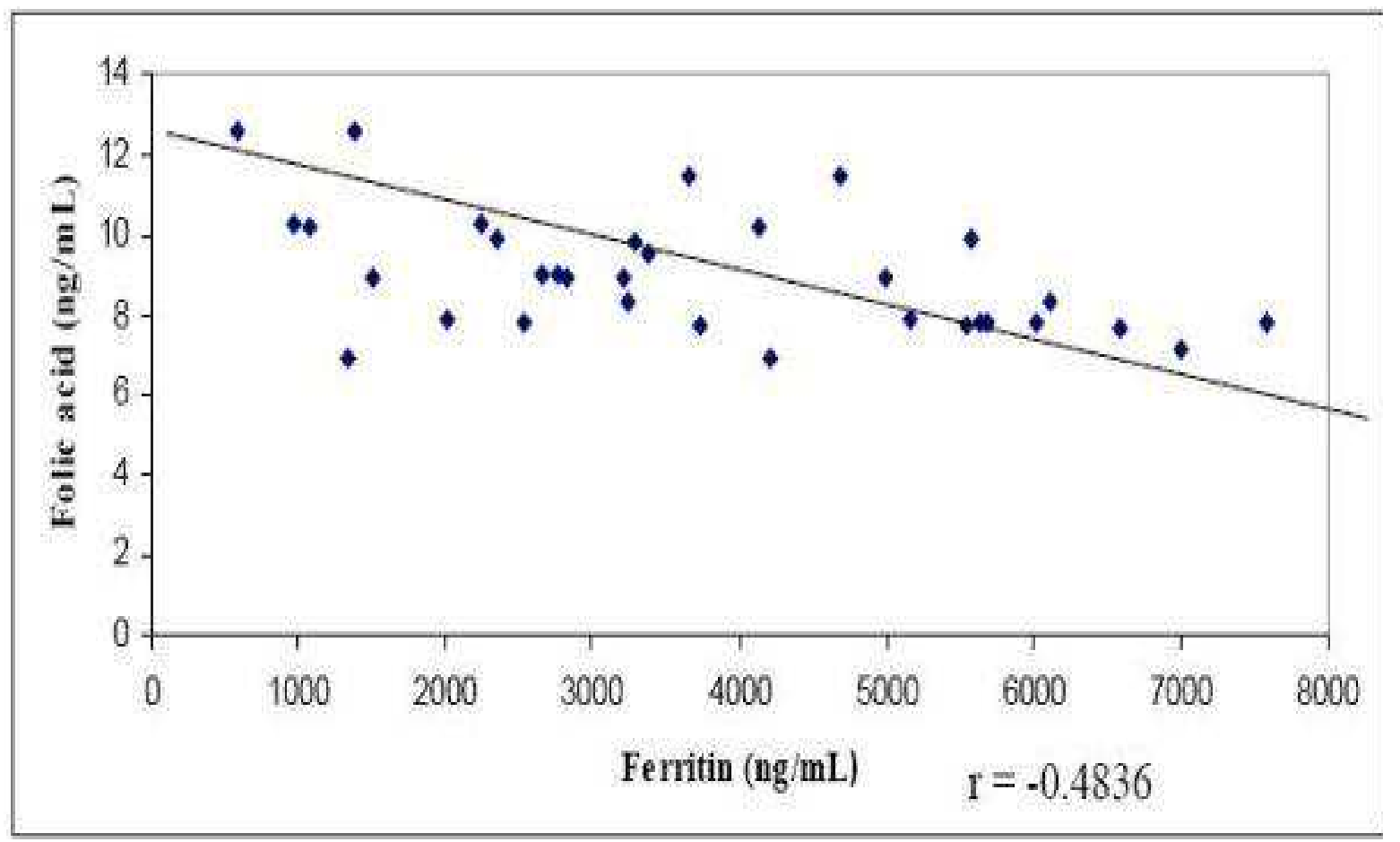

Figure-2: Scatter plot showing correlation between serum ferritin and folic acid levels

As can see from above figure, with increase in serum ferritin levels, there was corresponding decrease in the levels of serum folic acid in beta thalassemic children. Pearson's correlation coefficient ( $r$ value of -0.4836) indicates strong negative correlation between serum ferritin and serum folic acid levels. 


\section{Discussion}

Anaemia affects a significant proportion of children in developing countries. Nutritional deficiencies like iron, vitamin $B_{12}$ and folic acid are also very frequent in these areas [19]. So for treatment of anaemia, we need detailed evaluation to find out the exact cause.

In our study, thalassemic patients had much higher ferritin levels in comparison with healthy controls. Their PBF picture showed microcytic hypochromic picture. Microcytosis may lead to confusion with iron deficient state. So these patients sometimes receive costly and unnecessary iron treatment. [20] Hence knowing iron levels is of utmost importance in these patients to avoid harmful effects of iron overload in early stages of the disorder [21]. On other hand in iron deficiency anaemia, ferritin levels are decreased and these patients need iron treatment.

In our present study, children with beta thalassemia were found to have significantly lower vitamin B12 and folic acid levels as compared to healthy controls $(\mathrm{p}<$ $0.001, \mathrm{p}<0.001$ respectively). The healthy controls had normal vitamin B12 levels (180-971pg/ml)[17], as well as normal levels of folic acid (>6 ng/ml[18].

According to a study by Crayn et al, the most important $\mathrm{PBF}$ findings of vitamin $\mathrm{B}_{12}$ and folic acid deficiency are macrocytic RBCs and hypersegmented neutrophils [22]. This increase in RBCs size may be masked by microcytosis of co-existing iron deficiency or thalassemia. So normal MCV levels may be seen in up to one-thirds of the patients with vitamin $B_{12}$ deficiency[23]. Hence haematological picture alone in these thalassemic patients cannot provide complete insight to guide their treatment.

Our study illustrated strong negative correlation between serum ferritin and vitamin $B_{12}$ levels in the thalassemic study group $(r=-0.72, p<0.001)$, as shown in Figure 2. The negative relationship between serum ferritin and vitamin $\mathrm{B}_{12}$ may be due to increased synthesis of HbA2 in thalassemic patients.[24] A study by Tamagnini GP et al also illustrated vitamin $B_{12}$ defficiency in patients of beta thalassemia [25].

Our study showed strong negative correlation between serum ferritin levels and serum folic acid levels in the thalassemic study group $(r=-0.483, p<0.001)$, as shown in Figure 3. A study by Silva $\mathrm{A}$ et al with similar findings support our results [26]. Another study demonstrated salutary effect of folate administration in beta thalassemic patients [27].

Hence since vitamin $\mathrm{B}_{12}$ and folic acid facilitate normal erythropoiesis, keeping their blood levels normal is very essential in beta thalassemic patients.

Key message and Conclusions- Biochemical screening for the levels of serum ferritin, folic acid and vitamin $B_{12}$ is of utmost importance in beta thalassemic patients of paediatric age group. The increased serum ferritin, and decreased serum vitamin $\mathrm{B}_{12}$ and folate add to ineffective erythropoiesis in beta thalassemic patients.

Their PBF picture of microcytosis may lead to confusion with iron deficiency anaemia.

Hence these anaemic children should be thoroughly investigated so that proper treatment is instituted to avoid the cost and side-effects of unnecessary medications like iron therapy. Our study could be beneficial for thalassemic patients as vitamin B supplementation can be useful in these patients who have proven deficiency of these vitamins, though further studies are required to prove the hypothesis.

Acknowledgements: The authors are thankful to all the volunteers who participated in the study.

Roles of authors: The corresponding author Dr. Heena Singla carried out the complete study and wrote the manuscript. Dr. Gitanjali Goyal contributed to revision of the manuscript and discussion.

Disclosure statement: The authors approve that this final article is true. The authors have materially participated in the research and article preparation.

Funding: Nil, Conflict of interest: None initiated, Permission from IRB: Yes

\section{References}

1. Weatherall DJ, Pressley L, Wood WG, Higgs DR, Clegg JB. Molecular basis for mild forms of homozygous beta-Thalassaemia. Lancet 1981; 1(8219): 527-529. PMID: 6109998

2. Tyagil S, Kabra M, Tandon N, Saxena R, Pati HP, Choudhary VP. Clinico-haematological profile of thalassemia patients. International Journal of Human Genetics 2003; 3: 251-258. PMCID: PMC 3955643. 
3. Maheshwari M, Sadhna A, Kabra M, Menon PSN. Carrier screening and prenatal diagnosis of Betathalassemia. Indian Paediatrics 1999;36(11):1119-1125.

4. Andrews NC. Disorders of Iron Metabolism. New England Journal of Medicine 1999; 341(26): 19861995. PMID: 10607817

5. Kong WN, Zhao SE, Duan XL, Yang Z, Qian ZM, Chang YZ. Decreased DMT1 and increased Ferroportin 1 expression is the mechanism of reduced iron retention in macrophages by erythropoietin. Journal of Cell Biochemistry 2008; 104(2): 629-641.

6. Hershko C, Konijn AM, Link G. Iron chelators for thalassaemia. British Journal of Haematology 1998; 101(3): 399-406.

7. Granier T, Langlois d'Estaintot B, Gallois B, Chevalier JM, Precigoux G, Santambrogio $P$ et al. Structural description of the active sites of mouse Lchain ferritin at $1.2 \mathrm{~A}^{\mathrm{o}}$ resolution. Journal of Biological Inorganic Chemistry 2003; 8 (1): 105-111.

8. Ryan GM, Torelli J. Beyond cholesterol: 7 lifesaving heart disease tests that your doctor may not give you. New York: St. Martin's Griffin; 2005.

9. Kennedy A, Kohn M, Lammi A, Clarke S. Iron status and haematological changes in adolescent female in patients with anorexia nervosa. Journal of Paediatric Child Health 40 (8): 430-432.

10. Herbert V. The nutritional anaemias. Hospital Practice 1980; 15(3): 65-83.

11. Jandl JH, Greenberg MS: Bone marrow failure due to relative nutritional deficiency in Cooley's hemolytic anemia. New England Journal of Medicine 1959; 260: 461-468. Doi: 10.1056/NEJM.195903052601002.

12. Luhby AL, Cooperman JM, Lopez R, Giorgia AJ: Vitamin B12 metabolism in thalassemia major. Annals of New York Academy of Sciences 1969; 165: 444460. PMID: 4900400.

13. Yamada H, Saito H. Relationship between body storage iron and erythropoietic disorders. Acta haematologica Jpn 1982; 45: 1245-1257.

14. Thorpe SJ. Automated Immunoassay methods for ferritin. Clinical Chemistry Laboratory Medicine 2008;
46 (10): 1450-1457. Doi 10.1515/CCLM.2008.304.

15. Lotz J, Hafner G, Prellwitz W. Reference study for ferritin assays. Kurzmitteilung Clinical Laboratory 1997; 43(11): 993-994.

16. Clinical Laboratory Technical Procedure Manuals Approved Guidelines $-4^{\text {th }}$ edition 2006.

17. Smith AD, Refsum H. Do we need to reconsider the desirable blood levels of vitamin $\mathrm{B}_{12}$ ? Journal of Internal Medicine 2012; 271(2): 179-182.Doi:10. 1111 /j.1365-2796.2011.02485.x

18. Selhub J, Jacques PF, Dallal G, Choumenkovitch S, Rogers G. The use of blood concentrations of vitamins and their respective functional indicators to define folate and vitamin $\mathrm{B}_{12}$ status. Food and Nutrition Bulletin 2008; 29: 567-573. doi:10. 1177 / 1564826 5080292 S110.

19. Prakash VK.Nutritional anaemia in young children with focus on Asia and India. Indian Journal of Community Medicine 2011; 36(1): 8-16.

20. Asma S, Boga C, Ozdogu H. Safety, therapeutic effectiveness and cost of parenteral iron therapy. International Journal of Hematology 2009; 90(1): 24-7.

21. Kremastinos DT, Toutouzas PK, Vyssoulis GP, Venetis CA, Avgoustakis DG. Iron overload and left ventricular performance in beta Thalassemia. Acta Cardiology 1984; 39(1) 29-40.

22. Crayn, Elizabeth MD. Vitamin $B_{12}$ deficiency, recognition and management. Primary Care Case Reviews 2002; 5(2): 53-60.

23. Mazzone A, Vezzoli M, Ottini E. Masked deficit of $\mathrm{B}(12)$ and folic acid in thalassemia. American Journal of Hematology 2001; 67(4): 274. Doi 10.1002/ajh.1132

24. Henshaw LA, Tizzard JL, Booth K, Beard MEJ. Haemoglobin A2 levels in vitamin $B_{12}$ and folate deficiency. Journal of Clinical Pathology 1978; 31: 960962.

25. Tamagnini GP, Lopes MC, Castenheira ME, Wainscoat JS, Wood WG. $\beta$ - thalassemia-Portguise type: Clinical, haematologial and molecular studies of a newly defined form of $\beta$ thalassemia. British Journal of Haematology 1983; 54: 189- 200. 
26. Silva AE, Varella-Garcia M. Plasma folate and vitamin $\mathrm{B}_{12}$ levels in beta-thalassemia heterozygotes. Brazilian Journal of Medical and Biological Research 1989; 22 (10): 1225- 1228.Doi/10. 1002/ 97804706 96705.ref
27. Weatherall DJ, Clegg JB: The thalassemia syndromes. Oxford Blackwell Scientific Publications. Third edition, 1981.

\section{How to cite this article?}

Singla H, Goyal G. Role of Estimation of Serum Ferritin, Vitamin B12 and Folic Acid in Management of Beta Thalassemic Children. Int J Med Res Rev 2016;4(8):1476-1483.doi:10.17511/ijmrr.2016.i08.31. 